\title{
LAS DISTINTAS MANERAS DE ENTENDER LA REPRESENTACIÓN, REFLEXIONES A LA LUZ DEL DEBATE POLÍTICO ACTUAL EN CHILE*
}

\author{
Francisco Soto Barrientos** \\ Universidad de Chile, Chile \\ fsoto@derecho.uchile.cl
}

\begin{abstract}
RESUMEN: Este trabajo analiza cómo la acción autónoma de representantes políticos puede confrontarse discursivamente con otras formas de representación que surgen del debate deliberativo. Este tipo de conflictos generarían, en casos particulares, no sólo la deslegitimación de la autoridad electa por votación popular, sino consecuencias negativas en el propio sistema representativo. A nuestro juicio, dicha situación se produce en dos ejemplos que surgen de la actual coyuntura política en Chile: la utilización reiterada por el Gobierno del mecanismo de reemplazo de vacantes de senadores (previsto en el artículo 51 de la Constitución Política de la República) y las manifestaciones estudiantiles desarrolladas desde abril del 2011 a la fecha.
\end{abstract}

Palabras claves: Representación, ciudadanía, política, constitución.

\section{THE DIFFERENT WAYS OF UNDERSTAND THE REPRESENTATION, REFLECTIONS ABOUT THE ACTUAL AND PUBLIC DEBATE IN CHILE}

\begin{abstract}
This study analyzes how autonomous action by political representatives can discursively be compared against with other ways of representation that arise from deliberative debate. In particular cases such conflicts Generates, not only delegitimization of authority elected by popular vote, but negative consequences in the representative system itself. We believe this situation is evidenced by two instances that arise from the current political situation in Chile: repeated use by the Government of replacement mechanism senators vacancies (as provided for in the Article 51 of the Political Constitution of the Republic of Chile) and the student protests carried out since April 2011 to date.
\end{abstract}

Keywords: representation, citizenship, politics, constitution

Trabajo recibido el 20 de octubre y aprobado el 20 de noviembre de 2011.

** Abogado, Magister en Derecho Constitucional e Instituciones Públicas, Universidad Diego Portales. Doctor en Derecho, Universidad de Barcelona. Académico del Programa de Doctorado, Facultad de Derecho de la Universidad de Chile. 


\section{INTRODUCCIÓN}

El nombramiento de parlamentarios en altos cargos en el gobierno del Presidente Sebastián Piñera, ha generado un fuerte cuestionamiento en la opinión pública y reproches de parte de sus electores. Esto en atención a que la modalidad de reemplazo de las vacantes dejadas por los referidos senadores, según el reformado artículo 51 de la Constitución, es entregada discrecionalmente al partido político al que pertenece el parlamentario.

Esta fórmula de selección establecida en el año 2005, ha provocado la indignación de muchos que ven asumir a autoridades que no cuentan necesariamente con el beneplácito de sus representados.

La molestia ciudadana tiene alguna base en nuestra tradición constitucional, que tendió a dar mayor consideración a los representados al momento de establecer mecanismos de remplazo de los parlamentarios. En efecto, entre 1818 y 1888 operó la figura de los "senadores suplentes" que se definían al momento de la elección. Por su parte, la carta de 1925 establecía la alternativa de elecciones extraordinarias. Incluso, el original mecanismo señalado en la Constitución de 1980 suponía que el lugar del parlamentario saliente correspondería a alguno de sus compañeros de lista.

Con todo, esta manera restringida de entender la representación tiene cierto arraigo en el modelo institucional propuesto en la Constitución de 1980. Es así como en el artículo cuarto se omite la expresión "representativa”, establecida en la Constitución de 1925, para caracterizar a Chile como una "República democrática". Además, en el artículo quinto se postula el principio de "soberanía nacional" dejando de lado el de "soberanía popular", también presente en la carta de 1925, lo que hace suponer que prima por sobre la voluntad "del pueblo elector", "la tradición" o "esencia del alma nacional", expresada a través de una serie de opciones institucionales sobre la participación política, el modelo institucional, los derechos fundamentales, entre otras materias que caracterizarían a Chile como nación a lo largo de su historia. ${ }^{1}$

De igual manera, es posible advertir una variante acotada de la representación en otras fórmulas constitucionales, por ejemplo, en la integración de órganos técnicos-profesionales como es caso del Poder Judicial, del Ministerio Público, Tribunal Constitucional, la Justicia Electoral, la Contraloría General de la República, las Fuerzas Armadas, de Orden y Seguridad Pública, el Consejo de Seguridad Nacional, el Banco Central, entre otros, cuyas autoridades no son electas directamente por la ciudadanía. Por lo tanto, hoy no debería sorprender que la designación popular sea un mecanismo más para determinar a las autoridades en Chile.

1 Guzmán, Jaime. "La Constitución Política", Discurso pronunciado en la IX jornada de Derecho Público, en: Revista Chilena de Derecho, vol. 6, Número 1-4, Santiago, 1979, pp. $53-78$. 
A partir de ello es posible hacerse la siguiente pregunta ¿Los chilenos al manifestar su molestia frente a estos sucesos estarían dando cuenta de una idea de representación desmesurada (van más allá de lo establecido en las normas constitucionales y legales) o bien se podría pensar que en nuestro país conviven dos o más ideas de representación?

Bobbio, se inclina por esta última tesis. Para este autor italiano los supuestos y principios sobre los que se ha fundado la democracia no siempre han sido los mismos y puede ser que en la ciudadanía existan diferentes ideas sobre esta forma de gobierno, incluso contrapuestas, que se expresen en la manera en que se ejerza la ciudadanía o representación. De tal suerte, que caracteriza al sistema democrático como cambiante o "dinámico", sujeto siempre a una constante interpretación o mutación de las instituciones. ${ }^{2}$

Esta noción generaría una multiplicidad de conflictos políticos si sólo nos concentramos en la idea de representación. Es así, como los derechos y obligaciones cambiarían para representante y representado según la idea que se adoptara. El panorama se hace más complejo aún, al constatar que a pesar de su creciente utilización en la práctica política, la idea de representación no ha tenido mayor desarrollo en la doctrina política.

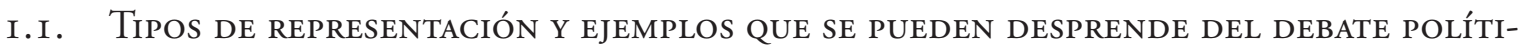 co aCtual en Chile}

Quizás el único de los grandes teóricos que se ha detenido en este concepto fue Hobbes. Particularmente, se refiere a él en el capítulo 16 del Leviatán llamado "De las Personas, Autores y cosas personificadas" donde sostiene que la ausencia de una idea de representación lleva al hombre a un estado natural, donde domina la auto -tutela y la lucha por sobrevivir. Para sacar a los hombres de esta situación, Hobbes no sólo utiliza la conocida idea del contrato social sino también su concepto de representación. La aproximación de este concepto, surge de la distinción entre persona natural (cuya palabra o acciones son consideradas como propias) y persona artificial (sus palabras surgen de los individuos que la representan). En este último caso, el actor actúa por autoridad, vale decir, “(...) que cuando el actor hace un pacto por autorización, obliga con él al autor, no menos que si hiciera este mismo, y no le sujetara menos, tampoco, a sus posible consecuencias". ${ }^{3}$ Así la idea de soberano se vincula a persona artificial, vale decir, a una autoridad facultada por los miembros de una sociedad para que actúe en su nombre. Se establece, de esta manera, el primer intento de entender representación a partir de un acto formal, ya que esta se define de manera previa, a través de una transacción entre representante y representado, expresada públicamente y de manera explícita en las elecciones. Así el acto electoral es simplemente una concesión de autoridad que los votantes hacen sobre agentes elegidos. A partir

Bоввіо, Norberto. El Futuro de la democracia,. D.F., México: Fondo de Cultura Económica, 1996, p. 15.

3 Новвеs, Thomas. Leviatán, o la materia, forma y poder de una República, eclesiástica y civil, -Traducción y prefacio de Manuel SÁnchez Sarto-,. D.F., México: Fondo de Cultura Económica, 1651, p. 133. 
de esta lógica se busca maximizar los derechos del representante, otorgándole una amplia libertad de acción desde el momento en que es electo. Como bien concluye Rawls, refiriéndose a esta perspectiva formalista, los actos de representante no pueden ser sujetos -desde esta manera de entender la representación- a escrutinio por los representados, forzándonos a optar por los extremos: un gobierno absoluto o la anarquía. ${ }^{4}$

Siguiendo con el análisis, la autora Hanna Fenichel Pitkin en su trabajo denominado "El concepto de representación", donde hace una revisión actualizada de los diversos usos que, la doctrina y la práctica política, han atribuido a la idea de representación estableciendo varias maneras de entenderla. Esta profesora de la Universidad de Berkeley da cuenta de la evolución de la tesis formalista (de Hobbes) en el desarrollo de las democracias representativas occidentales. Concluye que hoy en día una visión formalista de representación supone, a lo menos, establecer varias condiciones en los procesos electorales que no fueron considerados originalmente por el pensador inglés. En efecto, la autora sostiene que los actos electorales deben ser sucesivos, recurrentes en el tiempo y limitados a períodos de ejercicio del cargo (sujeto a representación). Sólo si se agregan estas exigencias sería posible entender la representación formalista en un Estado democrático. ${ }^{5}$

Con todo, Pitkin opone a la teoría formalista otra perspectiva que ella denomina: "teoría de la responsabilidad". De acuerdo con ésta, el representante debe dar cuenta de lo obrado al representado considerando que el primero adquiere nuevas y especiales obligaciones al asumir la calidad de representante. ${ }^{6}$

En este mismo sentido, creemos que unos de los primeros autores que argumenta acerca de la responsabilidad, sin profundizar mayormente, es John Locke. En el capítulo XIII del Segundo Tratado sobre el Gobierno Civil señala que el poder que ejerce el gobierno tiene características fiduciarias debido a que surge de la confianza otorgada por el pueblo a través del pacto social. Cuando se viola esa confianza, esta suerte de mandato que tienen los gobernantes se ve quebrantada y eventualmente el pueblo puede destituirlo. ${ }^{7}$ En la práctica, la teoría de la responsabilidad hoy supone contar con mecanismos de control o rendición de cuentas, estableciendo un alto estándar para entender un gobierno representativo: la presentación y cumplimiento de un programa asociado al representante. Se busca que los representantes sean sensibles a las necesidades y demandas de la población y que su representación esté vinculada con éstas.

4 Rawls, John. Lecciones sobre la historia de la filosofía politica, Barcelona, España: Paidós Ibérica, 2009, pp. 123 - 127.

5 Pitkin, Hanna Fenichel. El concepto de representación, Madrid, España: Estudios Políticos, Centro de Estudios Constitucionales, 1985, pp. $47-48$.

$6 \quad$ Ibid., p. 62.

7 Locke, John. Segundo tratado sobre el Gobierno Civil, Madrid, España: Alianza Editorial, 1690, pp. 154 - 163. 
Pitkin señala: "Asi, se puede considerar equivalente gobierno representativo y soberania popular, lo cual no quiere decir que los votantes decidan de hecho una politica legislativa, sino que quiere decir que los gobernantes politicos serian responsables ante los votantes en las elecciones periódicas." 8

Frente a este escenario, que reconoce dos concepciones extremas de representación, pensamos que el modelo institucional de Chile se aproxima más al formalista que a uno fundado en el criterio de responsabilidad. Por lo pronto, la propia fórmula presidencialista supone elecciones periódicas de autoridades, sin que éstas deban presentar un programa de compromisos cuyo incumplimiento acarre su destitución. Lo anterior, a diferencia de lo que ocurre con algunos modelos parlamentarios donde opera la figura de la investidura de los gobiernos que supone, en ciertos casos, la presentación de un programa. ${ }^{9} \mathrm{O}$ bien, en sistemas institucionales como el de Colombia, que si bien es de tipo presidencialista, se reconoce constitucionalmente el voto programático y la revocación de mandato. ${ }^{10}$

Con todo, el modelo chileno contempla una serie de opciones institucionales establecidas principalmente en el capítulo de Bases de la Institucionalidad y en el referido a los derechos y deberes constitucionales que caracterizarían a Chile como nación, en el sentido dado por Jaime Guzmán, y que es referida al inicio de este trabajo. Pues bien, desde esta perspectiva un representante una vez autorizado en una elección se debería más a los mandatos establecidos en la Constitución, que a los eventuales compromisos de campaña. Por ejemplo, esto sucedería con un parlamentario que promueva la eutanasia o critique el orden público económico, el modelo educativo o de salud, entre otras materias. Por tanto, nos encontramos ante un modelo que si bien, libera al representante de sus compromisos electorales, lo obliga a respetar las definiciones constitucionales (al elector expresado a lo largo del tiempo y no al que puntualmente lo eligió).

Hasta aquí el panorama parecía claro, sin embargo Pitkin sostiene que paralelamente a las formas de representación institucionalmente reconocidas (formalista o de responsabilidad) existen otras que se manifiestan en el debate deliberativo y que, eventualmente, podrían relacionarse en condiciones de igualdad e incluso confrontarse con las nociones normativas de la representación. Es así, como la autora da cuenta de una tercera modalidad de representación denominada descriptiva. La representación, mirada desde una perspectiva, implica reproducir, lo más fidedignamente posible, la posición de quien se representa. Se trata de una visión que opera, como seña-

\footnotetext{
Pitkin, Hanna Fenichel, op. cit. (n.5), p. 64.

9 Ver VinTró, Joan. La Investidura parlamentaria del gobierno: perspectiva comparada y constitución española, Madrid, España: Congreso de los Diputados, 2007.

10 En Colombia el referéndum para revocatoria de mandato de determinadas autoridades está estrechamente vinculada con el denominado "voto programático" previsto en el artículo 259 de la Constitución Política. La ley 741/2002 señala que procederá la revocatoria del mandato para gobernadores y alcaldes, al ser ella aprobada en el pronunciamiento popular por la mitad más uno de los votos ciudadanos que participen en la respectiva convocatoria, siempre que el número de sufragios no sea inferior al 55\% de la votación válida registrada el día en que se eligió a la respectiva autoridad. Pellegrino, Cosiminia: "Una introducción al estudio del referendo como mecanismo de participación ciudadana en la Constitución de 1999", en: ARISMENDI, Alfredo y Caballero, Jesús (coord.). El derecho público a comienzos del siglo XXI. Estudios en Homenaje al profesor Allan R. Brewer Carías, Tomo I, Madrid, España: Civitas Ediciones, 2003, pp. 441 - 483.
} 
lamos, fundamentalmente en el debate público y tiene como eje central la tarea de deliberar. En otras palabras, es representar el debate que se daría en la ciudadanía si pudieran hacerse presente todas las posiciones en un mismo momento y lugar. ${ }^{11}$ La perspectiva descriptiva estaría conectada con la alta valoración de la democracia de identidad y ve en la representación un segundo mecanismo de participación ciudadana. ${ }^{12}$

Para estos efectos, Pitkin da cuenta de casos donde los deseos del elector se ven satisfechos por el que ostenta el poder. Ve detrás de este fenómeno una identidad de imagen, donde el representado se iguala con el representante. Más que un representante "tipo", lo que el ciudadano busca es la identificación con un "tipo idea", un ideal del grupo. ${ }^{13}$ Un buen ejemplo de este tipo de representación lo encontramos en el movimiento estudiantil que actualmente se está desarrollando en Chile. En mi opinión, en este caso, el modelo de representación descriptiva operaría en dos niveles. En el primero se encuentran los estudiantes, donde podemos apreciar mecanismos de contacto directo entre los dirigentes y sus representados a través de actividades periódicas (asambleas estudiantiles y manifestaciones callejeras), que evidencian una relación inmediata y habitual entre los actores. De igual manera, también es posible distinguir una representación descriptiva en otros sectores de la opinión pública. Aquí se encuentran los colegios profesionales (particularmente el de profesores), los sindicatos y los apoderados en general, que ven en el movimiento estudiantil un discurso nuevo y alternativo, respecto del que hasta ahora ha sostenido los partidos con presencia en el Congreso.

Sin perjuicio del aporte que ha significado la perspectiva descriptiva para entender el fenómeno de la representación, esta no se agota con este tipo de análisis. Así se puede observar en el propio ejemplo del movimiento estudiantil anteriormente seńalado. En efecto, como sostiene Hanna Pitkin, en la práctica ningún representante puede actuar siempre como si estuviera en el lugar de sus representados, ya que esto significaría la anulación de su individualidad. Así esta autora identifica otra manera de representación llamada simbólica, que se diferencia de la descriptiva porque un símbolo no busca ser fiel imagen de lo representado. La exactitud de correspondencia no es lo que se pretende en la representación simbólica. Lo que prima, y precisamente le da valor a éste tipo de representación, es el potencial de suplencia emocional. ${ }^{14}$

A nuestro juicio, algo de representación simbólica ha logrado generar la Presidente de Federación de Estudiantes de la Universidad de Chile Camila Vallejo, que apela a la defensa de demandas que escapan en ocasiones a las reivindicaciones universitarias y se vincula a la imagen

11 Esta igualación entre representante y representado puede darse de tres maneras diferentes en el legislador: lo identifica a mapa o un espejo, esencialmente un objeto pasivo tan cercano que un espectador puede obtener información a partir de él; a un pintor o creador de representaciones, aquí se representa más por una actividad que por una composición; el legislativo seria una copia lo suficientemente precisa, entonces puede sustituir al pueblo, actuar en lugar de la nación.

12 Pitkin, Hanna Fenichel, op. cit. (n.5), p. 62.

13 Ibid., p. 87.

14 Ibid., p. 117. 
de los líderes latinoamericanos de izquierda. Así, el sitio web del diario británico The Guardian llegó a señalar, en referencia a esta dirigente, que: "desde los días del zapatista Subcomandante Marcos que no se ha visto a Latinoamérica tan encantada por un líder revolucionario". ${ }^{15}$

Quisiera hacer una breve referencia a otra de las formas de representar que analiza Pitkin, y que también pueden ser evidenciados en el actual debate político chileno. Estos vinculan la representación con las acciones de los sabios o expertos. Con frecuencia, este tipo de actividad cuando se relaciona con la política, supone un rol que le asigna el representado al representante.

"Al estar demasiado absortos por sus ocupaciones privadas, las gentes del pueblo eligen representantes políticos a fin de que se hagan cargo de la política por ellas, exactamente igual que eligen a un médico para que atienda su salud, y un abogado para que redacte escrituras o para que dirija sus pleitos(...). El verdadero representante obedece al pueblo al hacer las cosas que saben que éste quería hacer si tuviera su conocimiento, intuición y experiencia - como un médico cuando prescribe cosas ante las que su paciente se resiste y por las que siente aversión y sin embargo representa la voluntad real de su paciente de ponerse bien. La presunción de una habilidad o de conocimiento especializado en el representante sugiere que éste no necesita recibir órdenes de sus electores". ${ }^{16}$

Este planteamiento nos podría hacer pensar que el hombre medio carecería de pericia y conocimiento para gobernar. Pitkin ve diferencias entre el actuar de un especialista y de un representante político porque en el mundo político predomina la diferencia:

"Es significativo que siempre que un problema de ciencia especializada es discutible entre sus facultativos, y a la vez, es importante para el público, se le arroja a la esfera política, convirtiéndose en un problema para cuya solución el pueblo desea representación". 17

Lo importante de todas estas formas de representación que operan, en muchos casos sólo a nivel del debate público y no logran ser reconocidas institucionalmente, con todo de igual manera, compiten por la legitimidad de la autoridad en el espacio público. Así, frente a una decisión que comprometa un cierto nivel de deliberación pueden integrarse o superponerse de forma colaborativa dos o más tipos de representación. Por lo demás, es muy habitual que las autoridades electas se apoyen en otras formas de representación para fortalecer su legitimidad.

Dentro de nuestra experiencia política es posible encontrar casos muy interesantes en los que confluye la legitimidad formalista con la simbólica y la de expertos. En efecto, la ex Presidenta Michelle Bachelet detentaba su cargo entremezclando su nueva función presidencial

\footnotetext{
15 The Guardian, "Dozens injured after clashes on day two of Chile’s strike", 26 de Agosto de 2011, <En línea>, [citado el 12 de Octubre de 2011], disponible en la World Wide Web: <http://www.guardian.co.uk/world/2011/aug/26/two-chile-nationwidestrike-violences.

16 Pitkin, Hanna Fenichel, op. cit. (n.5), pp. 148 - 149.

$17 \quad$ Ibid., p. 150.
} 
con la imagen de víctima de la dictadura, militante socialista, médico, madre, mujer separada y agnóstica. Asimismo, encontramos ejemplos en que los que converge la legitimidad formalista con la del experto. Es el caso de la "nueva forma de gobernar" del Presidente Pińera, que en sus inicios se caracterizó por el alto número de empresarios e ingenieros comerciales, con posgrado en el extranjero, que fueron designados como Ministros o Subsecretarios, alcanzando su punto más alto de popularidad con el rescate de los mineros atrapados en una mina ubicada en la Región de Atacama en septiembre del 2010.

Es importante señalar que las diferentes formas de representación también pueden entrar en conflicto. En el Chile del 2011 surgen claros ejemplos vinculados con el debate que se ha generado en educación, donde se confronta una representación formalista de las autoridades públicas con la generada por el movimiento estudiantil que apela a fórmulas de representación descriptiva y simbólica como hemos señalado anteriormente.

Aquí el conflicto entre distintas formas de representación asume una dimensión dramática, ya que se expresa en la disminución sistemática y explosiva de la aprobación a la gestión del Presidente Piñera. La cual ha llegado, en el mes de agosto del 2011, a niveles históricos de descrédito, inédito en la política chilena: un apoyo al gobierno de sólo $22 \%$ y consecuente rechazo de un 66\% (según encuesta del Centro de Estudios de la Realidad Contemporánea, en adelante CERC).

La crisis está claramente vinculada con el modelo de representación extremamente formalista de la Constitución de 1980, ya que el juicio público permea el desempeño de los partidos políticos, instituciones que tradicionalmente construyen su representación mediante elecciones, que sólo cuentan con la aprobación de un $9 \%$ según la citada encuesta CERC. Esto se puede constatar también en la valoración que asume la alternativa de la consulta directa (llamado por la referida encuesta plebiscito educacional, con un $71 \%$ de apoyo como fórmula adecuada para resolver el conflicto). Esto supone, lógicamente, que la ciudadanía considera que los representantes electos no contarían con la confianza ciudadana para efectuar los cambios que se suponen necesarios en la educación chilena.

El deterioro en la percepción de representación formalista va de la mano con el aumento en los otros tipos de representación (descriptiva y simbólica) que hemos identificado en el movimiento estudiantil. Así según la antes referida encuesta CERC, un 89\% de los chilenos, apoya las demandas de los estudiantes, desplazando otros temas vistos como prioritario por los chilenos (delincuencia, temas económicos, entre otros).

La consecuencia de esto queda en evidencia: la socavación sistemática de la legitimación que sustenta la representación de autoridades políticas. No deja de llamar la atención, que en la 
referida encuesta CERC identifique un fuerte cambio, durante las manifestaciones estudiantiles, a favor de una reforma Constitucional, aumentando del 48\% que había en julio de 2009 al $75 \%$ en agosto de $2011 .{ }^{18}$

\section{i.2. Conclusión: Hacia una institucionalidad QUe integre una visión sustantiva DE REPRESENTACIÓN}

Los potenciales efectos negativos que puede generar un modelo sustentado en una representación formalista son anticipados por Pitkin, quién propone avanzar en un nuevo concepto de representación política:

“(...) representación significa aqui actuar en interés de los representados, de una manera sensible ante ellos. El representante debe actuar independientemente; su acción debe significar discreción y discernimiento; debe ser él quién actúe. El representado debe ser también (se le concibe como) capaz de acción y de juicio independiente, y no comportarse como necesitado de cuidado."19

Como vemos, Pitkin valora la acción autónoma del representante en la medida que no entre en conflicto con la voluntad expresa manifestada permanente por su comunidad y sin contar con sólidos argumentos que justifiquen su conducta. Desde este punto de vista, según la autora, sólo podrían establecerse límites externos a una idea sustantiva de representación. Éstos dependerían de la idea de representación que recoja cada sistema institucional, de acuerdo a la naturaleza de los intereses, a la capacidad de representantes y electores, entre múltiples factores. La posibilidad de contar con deliberación de cierto nivel y de procesos electorales que se ajusten a la ley, resulta clave para que pueda darse esta relación dinámica entre autoridad y elector. ${ }^{20}$

Siguiendo a Pitkin, por mucho que una institucionalidad satisfaga todos los estándares formales, si no contempla instancias que permitan (aunque sea potencialmente) activar la función propositiva de la ciudadanía, no llegará a constituir un sistema representativo en su expresión sustantiva. ${ }^{21}$ También es menester tomar en cuenta, como dice esta profesora de Berkeley, el complejo tramado de factores que presume la representación política. Efectivamente, tanto representantes como representados se ven influidos por un sin número de elementos de ord cultural, político y social que hace que su posición sobre determinadas materias sea parte de posturas colectivas y no individuales. Más aún, afirma que "los científicos de la política saben hace mucho tiempo que votar es esencialmente una experiencia de grupo". ${ }^{22}$

\footnotetext{
18 Hunneus, Carlos: "El 22\% de Piñera: un tsunami político", en: El Mostrador.cl, <en línea>, [citado el 30 de septiembre de 2011], disponible en la World Wide Web: <http://www.elmostrador.cl/opinion/2011/09/30/el-22-de-pinera-un-tsunami-politico/>.

19 Pitkin, Hanna Fenichel, op. cit. (n.5), p. 233.

20 "La representación es imposible- dice la autora- (excepto en un sentido descriptivo, simbólico o formalista) allí donde se exige una relación totalmente arbitraría, donde la deliberación y la razón son irrelevantes. Necesitamos precisamente alli donde no nos contentamos con abandonar las cuestiones en manos de expertos (...)". Ibid., p. 236.

21 Ibid., p. 237.

22 Ibid., p. 248.
} 
Aquí juega un papel fundamental la conformación y dinamismo de la opinión pública de la sociedad. El sistema representativo debe perseguir el interés público y para ello debe sensibilizar a los ciudadanos. Esto se encuentra fuertemente determinado por los medios de comunicación, los intereses económicos, los partidos políticos y demás grupos de poder que, generalmente, buscan que el público se quede con "simples apuntes positivos o negativos" de una propuesta y no con el contenido temático de dicha iniciativa. La presencia de un tramado de organizaciones, a la que puede o no pertenecer el elector, enriquece y da crecientes niveles de profundidad a la opinión pública dando respuestas "racionales" a los conflictos. Esto último posibilita, en definitiva, que tanto representantes como representados puedan actuar como sujetos activos y se conformen los supuestos de una verdadera representación. ${ }^{23}$

En este sentido, la posibilidad de contar con instituciones que permitan resolver conflictos suscitados por representantes y la voluntad claramente manifestada de la ciudadanía, se transformaría en una herramienta clave para cualquier democracia representativa.

En definitiva, lo único que se puede hacer, dice la autora, es aclarar cuál es la perspectiva de representación que se está utilizando cuando se interpreta, y si los supuestos e implicaciones se aplican para el caso en cuestión. ${ }^{24} \mathrm{~A}$ lo referido, Pitkin adiciona una reflexión particular sobre los "gobiernos representativos". Es así como señala que en la práctica se han ido estableciendo ciertas condiciones que permiten considerar cuándo un gobierno es representativo: elecciones regulares, genuinas y libres; que la toma de decisiones no esté entregada a un único gobernante y que exista un cuerpo representativo colegiado con algo más que capacidad consultiva.

No sería suficiente la acción dedicada de los gobernantes por actuar a favor del pueblo. El supuesto de que la ciudadanía "actúan a través" de sus representantes, parte de la idea de considerar una voluntad mayoritaria claramente manifestada en el tiempo. El gobierno representativo requiere instituciones lo suficientemente eficaces para lograr captar la voluntad ciudadana. Esta última no requeriría ser expresa, ni formulada para ser anticipada por la institucionalidad, pero si llegaran a manifestarse sus deseos deberían ser cumplidos o, al menos, existir buenas razones para que ocurra lo contrario. Resultaría incompatible con la idea de representación un tipo de gobierno que, de manera permanente y continuada en el tiempo, frustrara los deseos del pueblo. Asimismo, la representación sustantiva propuesta por Pitkin nos permite diferenciarla de simples manipulaciones políticas hechas en nombre del pueblo. El liderazgo representativo supone una ciudadanía empoderada y partícipe de la medida en cuestión. La acción manipuladora se impone con resistencia ciudadana o con simple indiferencia, pero siempre tiende a quedarse sola. Concluye:

23 Ibid., p. 249.

24 Ibid., p. 253 
"No decimos que un gobierno es representativo hoy porque ocurre que responde a los deseos populares, y que deja de serlo al día siguiente porque se frustra. El gobierno representativo no se define mediante acciones particulares en un momento concreto, sino por acuerdos de largo plazo, mediante instituciones y por la forma en que estas funcionan." 25

En definitiva, debido a la carencia de un concepto uniforme y sustantivo de representación, Pitkin tiende a centrar el eje del debate en los mecanismos de participación (si el modelo en cuestión supone más o menos participación directa de la ciudadanía), dejando de lado la manera en que los ciudadanos implementan dichas fórmulas democráticas. Esta autora concluye que la mejor manera de enfrentar la consulta acerca de cuándo un gobierno es representativo, es demostrando el verdadero control que ejercen los ciudadanos en la actividad de los gobernantes, más que al revés. ${ }^{26}$

En este sentido, la molestia ciudadana referida al mecanismo de reemplazo de los parlamentarios, establecido en el artículo 51 de la Constitución, debe ser entendida como una alerta más de las tantas a que nos hemos referido en este trabajo. Entre ellas, el desgaste que evidencia el modelo institucional chileno y la necesidad de cambios que permitan que los inevitables cuestionamientos sociales generados en el debate deliberativo, fortalezcan y no debiliten la representación política en Chile.

\section{REFERENCIAS BIBLIOGRÁFICAS}

Boвbio, Norberto. El Futuro de la democracia. D.F., México: Fondo de Cultura Económica, 1996.

Guzmán, Jaime. "La Constitución Política”, Discurso pronunciado en la IX jornada de Derecho Público, en: Revista Chilena de Derecho, vol. 6, Número 1-4, Santiago, Chile, 1979, pp. 53 - 78.

Новвеs, Thomas. Leviatán, o la materia, forma y poder de una República, eclesiástica y civil, -Traducción y prefacio de Manuel Sánchez Sarto-. D.F., México: Fondo de Cultura Económica, 1994.

Locke, John. Segundo tratado sobre el Gobierno Civil, Madrid, España: Alianza Editorial, 1690.

Pitkin, Hanna Fenichel. El concepto de representación, Madrid, España: Centro de Estudios Constitucionales, 1985.

Rawls, John. Lecciones sobre la historia de la filosofía política, Barcelona, España: Paidós Ibérica, 2009.

The Guardian, "Dozens injured after clashes on day two of Chile's strike”, 26 de Agosto de 2011, <En línea>, [citado el 12 de Octubre de 2011], disponible en la World Wide Web: <http://www.guardian.co.uk/world/2011/ aug/26/two-chile-nationwide-strike-violences.

VINTRÓ, Joan. La Investidura parlamentaria del gobierno: perspectiva comparada y constitución española, Madrid, España: Congreso de los Diputados, 2007.

25 Ibid., p. 257.

26 "Todas las acciones del gobierno (dice PITKIN) son atribuidas a sus súbditos formalmente, legalmente. Pero en un gobierno representativo esta atribución tiene un contenido sustancial: el pueblo actúa realmente a través de su gobierno, y no es un mero receptor pasivo de las acciones de éste. Un gobierno representativo no debe controlar simplemente, no debe promover simplemente el interés público, sino que debe también ser sensible al pueblo." Ibid., p. 257. 